\title{
The Compatibility between Fibonacci Sequence and Elliott Impulse Wave in the Context of A-share Market
}

\section{Yufeng Sang*}

Beijing University of Technology, Department of Construction Engineering, Beijing 100124, China. Email: 838727089@qq.com

Abstract: The connections between Fibonacci sequence and Elliott impulse wave that Ralph Elliot has proposed in Elliott Wave Principle are not valid all the time owing to the type and variability of the stock market. It is a probabilistic event which can reflect the compatibility between Fibonacci sequence and Elliott impulse wave. In order to explore the compatibility between Fibonacci sequence and basic-form Elliott impulse wave in the context of Chinese A-share market, a research via analyzing the historical trend of 50 core assets' individual stocks was conducted in Chinese A-share market. The study reveals that Fibonacci sequence does not highly fit basic-form Elliott impulse wave in the context of Chinese A-share market. Suggestions for investors are diversifying the investment strategy to enhance risk controllability, rather than using Elliott Wave Principle singly.

Keywords: Fibonacci Sequence; Golden Ratio; Basic-form Impulse Wave; A-share Market

\section{Introduction}

Fibonacci sequence has an intuitive form of $1,1,2,3,5,8,13,21 \ldots$, and meet the expression of: $F(1)=1, F(2)=1$, $\mathrm{F}(\mathrm{n})=\mathrm{F}(\mathrm{n}-1)+\mathrm{F}(\mathrm{n}-2)\left(\mathrm{n}>=3, \mathrm{n} \in \mathrm{N}^{*}\right)$. The ratio of two adjacent Fibonacci numbers converges to 0.618 when " $n$ " approaches infinity, which called golden ratio ${ }^{[1]}$. The other ratios, including $0.382,1.618,2.618$, are closely related to the golden ratio $^{[2]}$.

There are some major theories in Elliott Wave Principle. The trend of share price reflects a "basic pattern" consists of 5 impulse waves $(1,3,5, \mathrm{a}, \mathrm{c})$ and 3 corrective waves $(2,4, \mathrm{~b})$. Each impulse wave consists of 5 lower-level waves $\left(1^{\prime}, 2^{\prime}, 3^{\prime}, 4^{\prime}, 5^{\prime}\right)$, while each corrective wave consists of 3 lower-level waves $\left(a^{\prime}, b^{\prime}, c^{\prime}\right)^{[3]}$.

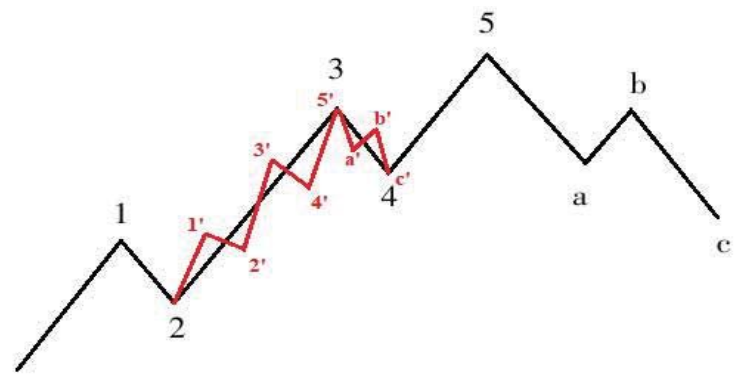

Figure 1. Basic form of Elliott Wave.

This is an open-access article distributed under the terms of the Creative Commons Attribution Non-Commercial License (http://creativecommons.org/licenses/by-nc/4.0/), which permits unrestricted non-commercial use, distribution, and reproduction in any medium, provided the original work is properly cited. 
The discussion of the regulations between Fibonacci sequence and Elliot impulse wave occupies a great deal of space and a crucial position in Elliott Wave Principle. In this principle, Ralph Elliot has indicated that Fibonacci sequence and golden ratio have some connections with a basic-form impulse wave in the context of the stock market via analyzing DJIA (Dow Jones Industrial Average):

(1) The range of wave 3 is often 1.618 or 2.618 times that of wave 1.

(2) The range of wave 5 is often 2.618 times or equals to that of wave 1.

(3)The range of wave 5 may also approach 0.618 times that of the net price from wave 1 to wave $3^{[4]}$.

Using these regulations, we can forecast the trend of an individual stock. However, these connections do not appear all the time thanks to the type and variability of the stock market ${ }^{[5]}$. This is a probabilistic event which reflects the compatibility of these regulations. The frequency that Fibonacci sequence occurs in a basic-form impulse wave, and the frequency that Fibonacci sequence totally fits a single basic-form impulse wave, both are the two indexes employed to define the compatibility of these regulations, while the research will be conducted around these two indexes.

\section{Methods}

\subsection{Research object}

Individual stocks of 50 core assets become the research objects since they considerably influence and practically represent the trend of A-share market. Each individual stock of a core asset has different-level Elliot waves in their $\mathrm{K}$-line diagram and the most distinctive basic-form impulse wave is convenient to distinguish and analyze ${ }^{[6]}$. K-line diagram has different type in the length of cycle including 1-minute line, 5-minute line, 15-minute line, 30-minute line, 60-minute line, day line, week line, month line. The shorter the cycle is, the more details will be emerged, yet it is difficult to reflect a complete trend. The longer the cycle is, the more integrated trend will be presented, yet the basic-form impulse wave is hard to distinguish ${ }^{[7]}$. This research adopts day line to be the cycle of K-line diagram since it is the most appropriate cycle to this research. In each day line of 50 core assets, the most distinctive basic-form impulse wave will be extracted to be a research object.

\subsection{Procedure}

\subsubsection{Raw data recording}

50 core assets picked to be the research objects were filtered from SSE 100 (an index which synthesizes 100 large scale, good mobility and most representative stocks filtered from Shanghai Stock Market via scientific and objective method). Each stock of the 50 core assets was adjusted to the day line to be the cycle of its K-line diagram. From this type of K-line diagram, the most distinctive basic-form impulse wave was extracted and measured the range of wave 1, wave 3 and wave 5 are measured. The net price from wave 1 to wave 3 was also measured. Eventually 50 sets of raw data were recorded with their exclusive stock codes in a table.

\subsubsection{Data processing}

In each set of raw data, the ratio of the range of wave 3 and wave $1\left(R_{3,1}\right)$, the ratio of the range of wave 5 and wave $3\left(R_{5,3}\right)$, the ratio of the range of wave 5 and the net price from wave 1 to wave $3\left(R_{5,1 \sim 3}\right)$ were eventually calculated and recorded in the table. Defining "the range of wave $n$ " as " $\mathrm{L}_{n}$ " $(\mathrm{n}=1,3,5)$ and "the net price from wave 1 to wave 3" as " $\mathrm{L}_{1 \sim 3}$ ", then the formulae can be expressed as:

$\mathrm{R}_{3,1}=\frac{\mathrm{L}_{3}}{\mathrm{~L}_{1}} ; \mathrm{R}_{5,3}=\frac{\mathrm{L}_{5}}{\mathrm{~L}_{3}} ; \mathrm{R}_{5,1 \sim 3}=\frac{\mathrm{L}_{5}}{\mathrm{~L}_{1 \sim 3}}=\frac{\mathrm{L}_{5}}{\max \left(\mathrm{L}_{3}\right)-\min \left(\mathrm{l}_{1}\right)}$

In the last formula, " $\max \left(\mathrm{L}_{3}\right)$ " is the maximum price of wave 3 while " $\min \left(\mathrm{L}_{1}\right)$ " is the minimum price of wave 1 , then " $\max \left(\mathrm{L}_{3}\right)-\min \left(\mathrm{l}_{1}\right)$ " is the net price from wave 1 to wave 3 .

\subsubsection{Data analysis}

For each set of data, introduces the parameter " $\mathrm{T}_{1}$ " and " $\mathrm{T}_{2}$ ". " $\mathrm{T}_{1}$ " and " $\mathrm{T}_{2}$ " refer to two dependent variables which are based on the independent variables " $R_{3,1}$ ", " $R_{5,3}$ " and " $R_{5,1 \sim 3}$ ". The two functional relationships can be expressed as: 


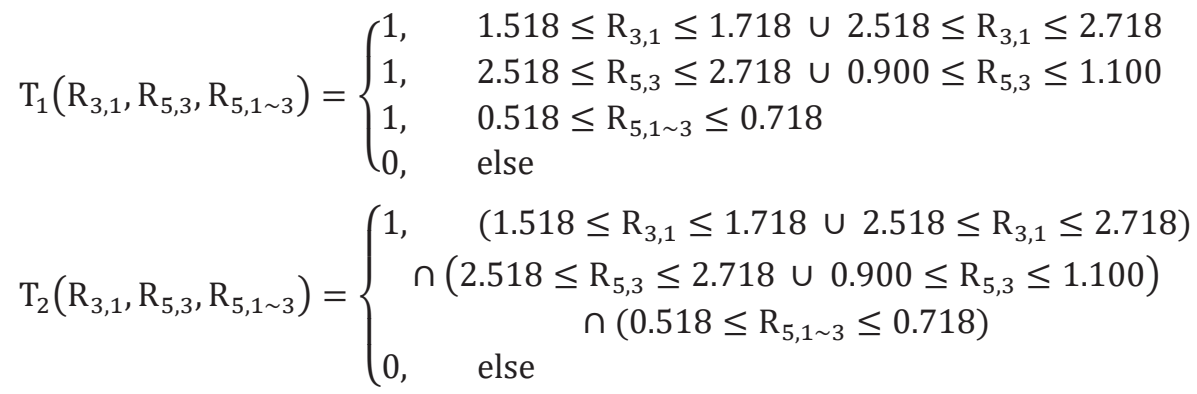

In each individual stock of 50 core assets, " $\mathrm{T}_{1}$ " can reflect if Fibonacci sequence occurs in the basic-form impulse wave, while " $\mathrm{T}_{2}$ " can reflect if Fibonacci sequence totally fits a single basic-form impulse wave. Acceptable error range was set as \pm 0.100 in this analysis.

Defining " $\left(\mathrm{T}_{1}\right)_{\mathrm{i}}$ " and " $\left(\mathrm{T}_{2}\right)_{\mathrm{i}}$ " as the numerical values of " $\mathrm{T}_{1}$ " and " $\mathrm{T}_{2}$ " of group $\mathrm{i}$ data, " $\mathrm{f}_{1}$ " as the frequency that Fibonacci sequence occurs in a basic-form impulse wave, " $\mathrm{f}_{2}$ " as the frequency that Fibonacci sequence totally fits a single basic-form impulse wave. Then the mathematical relationships between " $\mathrm{f}_{1}$ " and " $\left(\mathrm{T}_{1}\right)_{\mathrm{i}}$ ", " $\mathrm{f}_{2}$ " and " $\left(\mathrm{T}_{2}\right)_{\mathrm{i}}$ " can be expressed as follows:

$\mathrm{f}_{1}=\frac{\sum_{\mathrm{i}=1}^{50}\left(\mathrm{~T}_{1}\right)_{\mathrm{i}}}{50} \times 100 \% ; \mathrm{f}_{2}=\frac{\sum_{\mathrm{i}=1}^{50}\left(\mathrm{~T}_{2}\right)_{\mathrm{i}}}{50} \times 100 \%$

Eventually the two indexes " $\mathrm{f}_{1}$ " and " $\mathrm{f}_{2}$ " which are employed to define the compatibility between Fibonacci sequence and Elliott impulse wave were both calculated.

\section{Results}

The table shows the raw data " $L_{1}$ ", " $L_{3}$ ", " $L_{5}$ ", " $L_{1 \sim 3}$ ", intermediate variable " $R_{3,1}$ ", " $R_{5,3}$ ", " $R_{5,1 \sim 3}$ ", " $T_{1}$ ", " $T_{2}$ ". Among 50 individual stocks, there are 23 individual stocks whose " $\mathrm{T}_{1}$ " takes the value of " 1 ", while there are 11 individual stocks whose " $\mathrm{T}_{2}$ " takes the value of "1", meaning that Fibonacci Sequence occurs in the basic-form impulse wave for 23 times, and Fibonacci sequence totally fits a single basic-form impulse wave for 11 times.

The Table 2 shows the two indexes of each individual stock of 50 core assets, " $\mathrm{f}_{1}$ " and " $\mathrm{f}_{2}$ ". Using the numerical values of " $\mathrm{T}_{1}$ " and " $\mathrm{T}_{2}$ ", the numerical values of " $\mathrm{f}_{1}$ " and " $\mathrm{f}_{2}$ " were calculated as $46 \%$ and $22 \%$.

The line Figure 2 shows the 3 ratios of each stock. The minimum of " $R_{3,1}$ " is 0.324 , while its maximum is 3.918. The minimum of " $R_{5,3}$ " is 0.631 , while its maximum is 3.637 . The minimum of " $R_{5,1 \sim 3}$ " is 0.211 , while its maximum is 1.732 . 
Table 1. Raw Data and Intermediate Variable of Each Stock

\begin{tabular}{|c|c|c|c|c|c|c|c|c|c|c|}
\hline$\Delta$ & A & B & c & D & $\mathrm{E}$ & $\mathrm{F}$ & G & $\mathrm{H}$ & 1 & $J$ \\
\hline 1 & Code & $L_{1}$ & $L_{3}$ & $L_{5}$ & $L_{1 \sim 3}$ & $R_{3,1}$ & $R_{5,3}$ & $R_{5,1-3}$ & $T_{1}$ & $T_{2}$ \\
\hline 2 & 600703 & 5.63 & 9.31 & 23.58 & 37.85 & 1.654 & 2.532 & 0.623 & 1 & 1 \\
\hline 3 & 600340 & 8.58 & 278 & 7.78 & 4.49 & 0.324 & 2.799 & 1.732 & 0 & 0 \\
\hline 4 & 601211 & 3.36 & 109 & 3.26 & 2.60 & 0.325 & 2.987 & 1254 & 0 & 0 \\
\hline 5 & 601066 & 6.13 & 7.72 & 28.07 & 28.55 & 1259 & 3.637 & 0.983 & 0 & 0 \\
\hline 6 & 600029 & 223 & 3.57 & 3.19 & 9.49 & 1.602 & 0.893 & 0.336 & 1 & 0 \\
\hline 7 & 600837 & 2.73 & 8.07 & 23.37 & 18.59 & 2.956 & 2896 & 1257 & 0 & 0 \\
\hline 8 & 600031 & 234 & 3.73 & 1211 & 21.47 & 1596 & 3.242 & 0.564 & 1 & 0 \\
\hline 9 & 601288 & 0.52 & 101 & 1.13 & 1.26 & 1.933 & 1.125 & 0.899 & 0 & 0 \\
\hline 10 & 601988 & 0.34 & 0.56 & 0.55 & 0.56 & 1638 & 0.983 & 0.982 & 1 & 0 \\
\hline 11 & 601166 & 4.62 & 18.10 & 22.68 & 21.98 & 3.918 & 1253 & 1032 & 0 & 0 \\
\hline 12 & 601111 & 212 & 6.28 & 5.36 & 16.44 & 2.963 & 0.853 & 0.326 & 0 & 0 \\
\hline 13 & 601601 & 7.81 & 22.59 & 14.26 & 44.14 & 2.893 & 0.631 & 0.323 & 0 & 0 \\
\hline 14 & 601668 & 1.18 & 202 & 5.30 & 7.54 & 1.711 & 2623 & 0.702 & 1 & 1 \\
\hline 15 & 600887 & 4.01 & 6.77 & 17.49 & 25.38 & 1.689 & 2.582 & 0.689 & 1 & 1 \\
\hline 16 & 600016 & 0.56 & 114 & 265 & 2.15 & 2.032 & 2326 & 1233 & 0 & 0 \\
\hline 17 & 601229 & 3.23 & 5.23 & 13.76 & 13.45 & 1.618 & 2632 & 1.023 & 1 & 0 \\
\hline 18 & 600048 & 289 & 4.16 & 9.65 & 6.29 & 1.438 & 2323 & 1.536 & 0 & 0 \\
\hline 19 & 600519 & 177 & 289.93 & 739.02 & 752.57 & 1.638 & 2.549 & 0.982 & 1 & 0 \\
\hline 20 & 603993 & 0.78 & 254 & 5.67 & 5.16 & 3.254 & 2233 & 1099 & 0 & 0 \\
\hline 21 & 601398 & 0.54 & 0.88 & 2.34 & 3.74 & 1628 & 2657 & 0.624 & 1 & 1 \\
\hline 22 & 601186 & 1.33 & 2.07 & 1.85 & 3.02 & 1.559 & 0.894 & 0.613 & 1 & 0 \\
\hline 23 & 600028 & 0.53 & 1.58 & 4.58 & 3.46 & 2.981 & 2896 & 1.321 & 0 & 0 \\
\hline 24 & 601088 & 2.78 & 8.04 & 23.90 & 20.68 & 2.893 & 2972 & 1156 & 0 & \\
\hline 25 & 601939 & 121 & 1.93 & 4.71 & 6.82 & 1599 & 2.436 & 0.691 & 1 & 1 \\
\hline 26 & 601766 & 0.95 & 0.99 & 2.31 & 4.10 & 1.043 & 2332 & 0.564 & 0 & 0 \\
\hline 27 & 600309 & 8.27 & 8.71 & 2110 & 23.55 & 1.053 & 2423 & 0.896 & 0 & \\
\hline 28 & 600000 & 258 & 3.86 & 5.11 & 3.21 & 1.496 & 1325 & 1.593 & 0 & 0 \\
\hline 29 & 601318 & 21.34 & 56.17 & 55.55 & 103.25 & 2.632 & 0.989 & 0.538 & 1 & 1 \\
\hline 30 & 601688 & 4.24 & 11.19 & 1191 & 29.63 & 2638 & 1.065 & 0.402 & 1 & 0 \\
\hline 31 & 601328 & 0.82 & 2.43 & 3.05 & 224 & 2963 & 1254 & 1.36 & 0 & 0 \\
\hline 32 & 600690 & 3.02 & 4.95 & 1254 & 24.97 & 1638 & 2.534 & 0.502 & 1 & 0 \\
\hline 33 & 600585 & 9.83 & 13.02 & 38.88 & 31.10 & 1325 & 2985 & 1.25 & 0 & 0 \\
\hline 34 & 601390 & 0.92 & 2.44 & 2.58 & 4.35 & 2.647 & 1059 & 0.593 & 1 & 1 \\
\hline 35 & 600276 & 2278 & 57.47 & 150.47 & 214.34 & 2.523 & 2618 & 0.702 & 1 & 1 \\
\hline 36 & 600036 & 8.31 & 24.07 & 69.21 & 86.62 & 2.896 & 2876 & 0.799 & 0 & 0 \\
\hline 37 & 601628 & 1138 & 37.00 & 96.04 & 151.97 & 3.251 & 2596 & 0.632 & 1 & 0 \\
\hline 38 & 600104 & 4.51 & 6.43 & 16.96 & 23.72 & 1.425 & 2639 & 0.715 & 1 & 0 \\
\hline 39 & 601818 & 0.92 & 2.43 & 2.39 & 3.59 & 2639 & 0.985 & 0.667 & 1 & 1 \\
\hline 40 & 600030 & 9.53 & 20.57 & 18.55 & 25.94 & 2.158 & 0.902 & 0.715 & 1 & 1 \\
\hline 41 & 601336 & 13.52 & 19.36 & 57.75 & 57.98 & 1.432 & 2983 & 0.996 & 0 & 0 \\
\hline 42 & 600050 & 232 & 3.16 & 4.53 & 14.11 & 1.364 & 1.431 & 0.321 & 0 & 0 \\
\hline 43 & 601857 & 2.06 & 277 & 2.73 & 6.29 & 1346 & 0.983 & 0.433 & 0 & 0 \\
\hline 44 & 600019 & 1.06 & 133 & 208 & 2.18 & 1254 & 1566 & 0.954 & 0 & 0 \\
\hline 45 & 601989 & 126 & 207 & 206 & 3.01 & 1.639 & 0.996 & 0.683 & 1 & 1 \\
\hline 46 & 601800 & 2.56 & 4.86 & 8.03 & 8.60 & 1.899 & 1.652 & 0.934 & 0 & 0 \\
\hline 47 & 600196 & 4.31 & 7.74 & 15.37 & 60.73 & 1.796 & 1.985 & 0.253 & 0 & 0 \\
\hline 48 & 603259 & 25.62 & 76.48 & 154.86 & 733.95 & 2.985 & 2025 & 0.211 & 0 & 0 \\
\hline 49 & 601888 & 13.21 & 39.97 & 93.74 & 270.92 & 3.026 & 2.345 & 0.346 & 0 & 0 \\
\hline 50 & 601319 & 6.21 & 9.51 & 9.41 & 14.41 & 1.532 & 0.989 & 0.653 & 1 & 1 \\
\hline 51 & 601138 & 5.63 & 7.75 & 20.66 & 55.39 & 1.376 & 2.667 & 0.373 & 1 & 0 \\
\hline
\end{tabular}

Table 2. Two indexes: " $f_{1}$ " and " $f_{2}$ "

\begin{tabular}{|l|l|}
\hline$T_{1}$ & 23 \\
\hline$T_{2}$ & 11 \\
\hline$f_{1}$ & $46 \%$ \\
\hline$f_{2}$ & $22 \%$ \\
\hline
\end{tabular}

3 Ratios of Each Stock

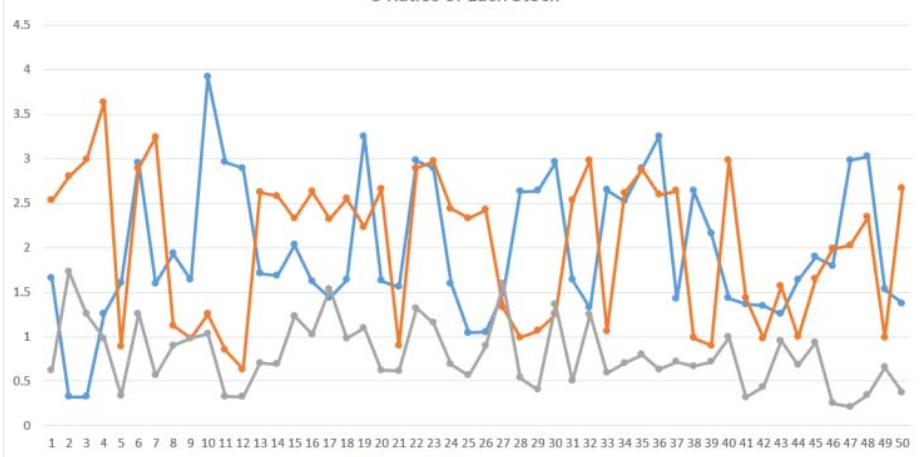

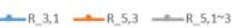

Figure 2. 3 ratios of each stock. 


\section{Discussion}

The purpose of this research was to evaluate the compatibility between Fibonacci sequence and Elliott impulse wave in the context of A-share market. The results show that Fibonacci sequence occurs in the basic-form impulse wave for 23 times, which occupies the $46 \%$ of individual stocks of 50 core assets, while Fibonacci sequence totally fits a single basic-form impulse wave for 11 times, which occupies the $22 \%$ of individual stocks of 50 core assets. The expected ranges are $50 \% \sim 60 \%$ and $20 \% \sim 30 \%$. Both proportions were lower than expected. This conclusion reflects the limitation of Elliott Wave Principle in Chinese A-share market, which not only comes from the different stock market context, but also owes to varieties of random factors ${ }^{[8]}$. The level and the extension of an impulse wave will both affect the appearance of Fibonacci sequence. These factors may come from the operation of different listed companies and the influence of Shanghai composite index.

The low proportions of the two conditions reveal the limitation of the regulations of Elliott Wave Principle in the Chinese A-share market. Actually, there are varieties of factors influencing the stock trend. Using a single mathematical ratio to predict the trend, it is a typical phenomenon to use phenomenon which exceptionally ignores the complexity and the high risks of the stock market. In other words, establishing investment decisions in a single mathematical configuration is an act of emptying realistic factors from the stock market.

If investors want to get more profits from an upward trend, they had better observe and summarize diverse indexes, pay more attentions to the changes in the securities market, diversify the investment strategy to enhance risk controllability, and consider when to exit in the uptrend and when to stop at the loss, rather than using a single trading mode. Last but not least, Elliott Wave Principle is worthy of being employed, but do not use it singly.

The limitation of this study mainly embodies the sample gap of the research project. The operation of listed companies may lead to the elongation of an impulse wave, therefore the pattern of impulse waves of the weak companies and the superior companies are quite different and they may reflect dissimilar information. Putting them together and centrally processing them will result in sample error ${ }^{[9]}$.

This research merely reveals the compatibility between Fibonacci sequence and Elliott impulse wave. Nevertheless, Elliott Wave Principle has corrective waves as the contrary of impulse waves. What can be further researched, synthesizing the impulse waves and corrective waves to dig out more comprehensive connections between Fibonacci sequence and Elliott Wave.

\section{References}

1. Hadis SE. Fibonacci squared. Trading Techniques 1999; $38-42$.

2. Rudy T. The Elliott-Fibonacci connection. Trading Techniques 2001; $52-54$.

3. Deng T. On the basic analysis of Elliott Waves Principle." (in Chinese) New Economy 2016; 20: 52 - 53.

4. Dunlap RA. The Golden Ratio and Fibonacci Numbers, World Scientific Publishing 1997.

5. Duan H. Elliott wave theory and the Fibonacci sequence-gray model and their application in Chinese stock market. Journal of Intelligent \& Fuzzy Systems 2018; 34: 1813 - 1825.

6. Zhu F. Some of the ratios in the Shanghai Composite Index, Association for Science and Technology 2010; 12: $139-140$.

7. Wang L. An Empirical Analysis of Eliot Wave Theory in China's Futures Market, China's Foreign Investment 2012; 4: $253-254$.

8. Liu H. "The existence of the Elliott wave model in China's stock market." (in Chinese) value engineering 2005; 5: $124-128$

9. Wang Z, et al. Research of the Elliott Wave Theory Applications Based on CBR. Intelligent System Design and Engineering Applications (ISDEA), Third International Conference on IEEE Computer Society 2013. 